\title{
Effect of Educational Nursing Protocol on minimizing Patients' complications after thoracoscopic surgery
}

\author{
Maha Nafady ${ }^{1}$, Magda Ahmed Mohammed ${ }^{2}$, Sahra Zaki Azer ${ }^{3}$ \& Hussein El Khayat ${ }^{4}$. \\ Assistant Lecturer in Medical-Surgical Nursing, Faculty of Nursing, Assiut University, Egypt. \\ Professor of Medical-Surgical Nursing, Faculty of Nursing, Assiut University, Egypt. \\ Assistant professor of Medical-Surgical Nursing, Faculty of Nursing, Assiut University, Egypt. \\ Lecturer of Cardiothoracic-Surgery, Faculty of Medicine, Assiut University, Egypt.
}

\begin{abstract}
Background: Video-assisted thoracoscopic surgery (VATS) is a minimally invasive surgical technique used to diagnose and treat problems in chest. This study aimed to assess the effect of educational nursing protocol on minimizing patients' complications after thoracoscopic surgery. Researsh design: Quasi experimental research design was used to conduct this study. The sample was consisted of a convenience sixty adult patients undergone thoracoscopic surgery. The following tools were utilized for data collection: An interview questionnaire sheet for patients, assessment sheet of patients' knowledge and practice, and assessment sheet for patients' complications. Results: There was highly statistical significance difference between study group patients pretest and posttest in total knowledge and practice after implementation of educational nursing protocol. There was no statistical significance difference between both groups as regard complications. Conclusion: There were improvements in total knowledge and practice after protocol implementation. Wound infection and pain were the only complications happened and with higher percentages in control group than study group. Recommendations: Educational nursing protocol should be given for patients in the form of video to be more understandable.
\end{abstract}

\section{Keywords: Complications, Educational Nursing Protocol \& Thoracoscopic Surgery.}

\section{Introduction}

Video-assisted thoracoscopic surgery (VATS) is a recently developed type of thoracic surgery performed using a small video camera that is introduced into the patient's chest via small incisions. The surgeon is able to view the instruments that are being used along with the anatomy on which the surgeon is operating. It is a minimally invasive surgical technique used to diagnose and treat problems in chest (Vallance et al., 2016).

Video-assisted thoracic surgery (VATS) is a way to look at the lungs and other tissue. A doctor puts a tiny telescope and surgical tools through small openings in the chest. The telescope is connected to a video camera that lets the doctor see a picture of the lungs. The patient may have to stay in the hospital for 1 to 3 days after surgery. Its main benefit has been the avoidance of a thoracotomy incision, which allows a shorter operating time, less postoperative morbidity, and earlier returns to normal activity (Vallance et al., 2016).

VATS is used in both diagnostic and therapeutic pleural, lung and mediastinal surgery. Its specific indications include stapled lung biopsy, lobectomy or pneumonectomy, resection of peripheral pulmonary nodule, evaluation of mediastinal tumors or adenopathy, bullectomy, treatment of recurrent pneumothorax, management of loculated empyema, pleurodesis of malignant effusions, repair of a bronchopleural fistula, chest trauma, pericardial window, sympathectomy and truncal vagotomy (Guerrini et al., 2016).

Absolute contraindications include markedly unstable or shocked patient and extensive adhesions obliterating the pleural space. Relative contraindications include inability to tolerate singlelung ventilation, previous thoracotomies, extensive pleural diseases, coagulopathy and prior radiation treatment for thoracic malignancy; plan to resect (Irons et al., 2016).

Complications of VATS include post procedural fever, pleural tears causing air leaks from the lung that don't heal up quickly and that can keep the patient in the hospital a longer time and occasionally require additional treatment. A very small number of patients have significant bleeding requiring a transfusion or larger operation. It is also possible, although not common, to develop an infection of the wound site or of the lung itself. Lung perforation, gas embolism and patients are also at risk of the complications of general anesthesia (Mu et al., 2013).

Other complications may include the following: Intercostal nerve damage due to insertion of instruments through the ports, Complications from single-lung ventilation, including respiratory insufficiency or postoperative re expansion pulmonary edema, Tumor implantation following VATS (Berry, 2015). 
Physiotherapists and thoracic ward medical and other staff perform a variety of care for patients undergoing surgery both pre and post operatively. All these are done to prevent postoperative complications like atelectasis, pneumonia, effusions and empyema. Various operations include education, deep breathing and coughing exercises, chest physiotherapy, early mobilization, prophylaxis exercises for deep vein thrombosis and shoulder exercises. Many other interventions like incentive spirometry have been shown to reduce the incidence of these complications (Gao et al., 2015).

The role of thoracic nursing specialty is to support and educate patients, who are suffering from thoracic diseases, to achieve the best outcome in terms of physical, psychological, social and spiritual well beings. The care provided not only focuses on inhospital treatments that patient received, but also encompasses the whole patient journey including lifestyle modification, health concept promotion, and self-empowerment (Yeung, 2016).

The provision of good quality preoperative information facilitates patient's active involvement in their care and may contribute to an overall increase in satisfaction. Preadmission information intervention helps reduce postoperative pain levels and significantly increases knowledge of self-care and complication management (White \& Dixon, 2015).

\section{Significance of the study}

From the researcher's clinical experience it has been observed that video-assisted thoracic surgery (VATS) is a new approach used in cardiothoracic surgery department instead of thoracotomy to treat several diseases. In the last year (2016) about 40 patients underwent thoracoscopic surgery without organized educational protocol for the patients either before or after the procedure. Therefore, this study was done to increase patients' knowledge about thoracoscopy and decrease its complications.

\section{Aim of the study}

The aim of this study was to assess the effect of educational nursing protocol on minimizing patients' complications after thoracoscopic surgery through:

- Assessing patients' knowledge and practice pre and post thoracoscopic surgery.

- Developing and implementing the educational nursing protocol for patients undergoing thoracoscopic surgery based on patients' needs assessment.

- Evaluating the effect of the educational nursing protocol on patients' complications.

\section{Research hypotheses}

The current study hypothesized that:
1. The mean knowledge scores of study group patients will be improving post the implementation of the educational nursing protocol.

2. The practice of study group patients will be improving post the implementation of the educational nursing protocol.

3. The frequency of thoracoscopic surgery complications will be less among the patients in the study group than the control group.

\section{Subjects \& methods \\ Research design}

Quasi experimental research design was utilized to conduct this study.

\section{I: Technical design}

Setting

This study was carried out in cardiothoracic surgery department at Assiut university hospital.

Subjects

The sample was 73 patients selected by using the following equation according to Steven, (2012)

$$
n=\frac{N \times p(1-p)}{\left.\left.\llbracket N-1 \times\left(d^{2} \div z^{2}\right)\right]+p(1-p)\right]}
$$

$\mathrm{N}=$ total patient population size of 90 who attended the cardio thoracic department at Assiut university hospitals for VATs, during year 2017-2018 by

$\mathrm{Z}=$ confidence levels is 0.95 and is equal to 1.96 , $\mathrm{D}=$ the error ratio is $=0.05$ and $\mathrm{P}=$ the property availability ratio and neutral $=0.50$.

Only 60 patients continue with the researcher to the end of follow up and the other 13 patients were excluded, 3 of them converted to thoracotomy and 10 not respond to telephone calls. The patients included were randomly assigned into 2 equal groups each one composed of 30 patients: group 1(study group): were exposed to educational nursing protocol beside routine hospital care and group 2 (control group) was exposed to routine hospital care only.

\section{Tools for data collection}

Data pertinent to the study were collected, utilizing the following three tools to achieve the purpose of the current study.

Tool (1) Patients' interview questionnaire

This tool was developed and modified by the researcher to assess demographic data and medical history for the patients included in the study. It developed by the researcher based on literature review. It was constructed based on the following parts:

Part one: It included demographic data of the patients as (name, age, sex, marital status, level of education, and occupation).

Part two: This part included medical history (present history). 
Tool (2) Interview questionnaire to assess patients' level of knowledge and practice (pre / post the implementation of the educational nursing protocol):

This tool was developed and modified by the researcher to assess knowledge and practice based on literature review. It was constructed based on the following parts:

Part one: It included pre / post assessment of patients' knowledge about thoracoscopic surgery (definition, indications, contraindications, advantages, complications, preparations, nursing care and instructions after discharge).

\section{Scoring system:}

Regarding patient knowledge about thoracoscopic surgery: This includes 13 questions: Scores assigned to each item are between 0 and 2 points as follows; (unknown, incomplete and correct). According to range of total scores lie between 0-26. Patients' knowledge was classified as: Satisfactory knowledge $\geq 50 \%$ and un satisfactory knowledge $<50$

Part two: It included pre / post patients' observation checklist (using spirometer, breathing and coughing exercises, foot and leg exercises, and hand and shoulder exercises).

\section{Scoring system:}

Regarding patient practice about thoracoscopic surgery: This includes 4 main exercises: Scores assigned to each step are between 0 and 2 points as follows; (not done, done incorrect and done correct). Patients' practice was classified as: Adequate practice $\geq 50 \%$ and un adequate practice $<50$

Tool (3) Interview questionnaire to assess patients' complications:

This tool was developed by the researcher based on patients' assessment of complications after one month postoperatively (wound infection, pain or numbness, pneumonia, air leak and death).

\section{II: Administrative design}

A letter was issued from the faculty of nursing at Assiut University to the head of cardiothoracic surgery department at Assiut University hospital, explaining the purpose of the study and requesting their permission for collecting the data.

\section{III: Operational design}

This study was carried out in two phases:

\section{Phase I: Preparatory phase}

A review of current and past, local and international related literature in the various aspects using books, articles, periodicals and magazines were done. The proposed study settings were assessed for the number of patients admitted to cardiothoracic surgery department who undergoing thoracoscopic surgery. This phase ended by contents validity and pilot study.
Content validity and reliability of the data collecting tools:

The content validity was done by 5 expertise (medical staff) from cardiothoracic surgery department \& (nursing staff) from the medicalsurgical nursing who reviewed the tools for clarity, relevance, comprehensiveness, understanding, applicability and easiness for administrative minor modifications were required and correction was carried out accordingly. As for the reliability, the tools were confirmed for consistency by cronbach's alpha coefficient (alpha $=0.829)$.

A pilot study

A Pilot study was conducted on $10 \%$ of sample (6 patients) admitted to cardiothoracic surgery department to test the feasibility and clarity of the tools. According to this pilot study, the required modifications were made. Those patients who were involved in the pilot study were included in the study. The purpose of the pilot study was: To ascertain the relevance of the tool, detect any problem might interfere with the process of data collection and to estimate the time needed to answer the study tools.

\section{Phase II: implementation phase}

Data were collected at the cardiothoracic surgery department at Assiut University Hospital during the period from October 2017 to December 2018. The tools were filled through interviewing and the purpose of the study was explained to all patients prior to collection of data. The study was carried out during morning and afternoon shifts for all available patients.

Once the permission was granted to proceed with the proposed study, the research proposal was submitted to the research committee at Assiut university hospital ,name of potential patients who have admitted to the unit and who met the criteria were obtained daily from the nurses and doctors in cardiothoracic surgery department at the hospital.

For the control group; after taking the patient oral agreement for voluntary participation in the study, the researcher then fills the patient's structured assessment tools preoperatively. After the patient's discharge from the hospital, the researcher calls the patient for follow up in telephone one month post thoracoscopic surgery to attend to outpatient clinic for re-evaluating the patient's condition including the complications that occurred.

For the study group; pre operatively after filling the patient's structured assessment tools, the researcher assess patients' practice and knowledge about thoracoscopic surgery, and then explains to the patient the educational nursing protocol which was developed by the researcher after passing through an extensive and relevant literature review based on patients' needs assessment. 
The educational nursing protocol was prepared in a simple Arabic language with a simple photo illustrations and contain everything about thoracoscopic surgery (overview about anatomy and functions of the thorax, pre - post care and follow up instructions about thoracoscopic surgery). It was administered to the patient in two sessions, the duration of each session was about 45 minutes, including 15 minutes for discussion and feedback, but the time may differ from one patient to another according to educational level and his $\backslash$ her ability to understand what is being said.

Each patient in the study group obtained a copy of the educational nursing booklet. Patients were evaluated for practice immediately post thoracoscopic surgery ,then after the patient's discharge from the hospital, the researcher calls the patient for follow up in telephone one month post thoracoscopic surgery to attend to outpatient clinic for re-evaluating the patient's condition include ( knowledge and complications).

\section{Ethical and legal consideration}

Confidentiality and anonymity of patients was assured through coding of all data. Each patient has right to withdraw each from the study at any time without any rational.

\section{Statistical design}

The statistical Package for (SPSS) version (23) was used to analyze data. Descriptive statistics was used for the quantitative data in the all questionnaire and the demographic data. Descriptive statistics included: frequencies, and percentages. Use Pearson chi-square (cross tabs test) between patient knowledge pre and post program. Independent t-test and one way anova was used, Pearson Correlation (Correlation is significant at the 0.05 level). The level of significance for this study was set at $(\mathrm{p} \leq 0.05)$ to detect any indication of differences found in the data available.

\section{Results}

Table (1): Frequency distribution of both groups (study and control) in relation to demographic characteristics $(n=60)$.

\begin{tabular}{|c|c|c|c|c|c|}
\hline \multirow{2}{*}{\multicolumn{2}{|c|}{ Variables }} & \multicolumn{2}{|c|}{ Study $(n=30)$} & \multicolumn{2}{|c|}{ Control $(n=30)$} \\
\hline & & No. & $\%$ & No. & $\%$ \\
\hline \multirow{4}{*}{ Age by years } & $18-<30$ years & 16 & 53.3 & 10 & 33.3 \\
\hline & $30-<41$ years & 1 & 3.3 & 5 & 16.7 \\
\hline & $41-<53$ years & 5 & 16.7 & 6 & 20.0 \\
\hline & $54-<65$ years & 8 & 26.7 & 9 & 30.0 \\
\hline \multirow{2}{*}{ Sex } & Male & 19 & 63.3 & 20 & 66.7 \\
\hline & Female & 11 & 36.7 & 10 & 33.3 \\
\hline \multirow{2}{*}{ Marital status } & Single & 14 & 46.7 & 11 & 36.7 \\
\hline & Married & 16 & 53.3 & 19 & 63.3 \\
\hline \multirow{4}{*}{ Level of education } & Not educated & 6 & 20.0 & 10 & 33.3 \\
\hline & Primary & 5 & 16.7 & 5 & 16.7 \\
\hline & Intermediate & 8 & 26.7 & 9 & 30.0 \\
\hline & High & 11 & 36.7 & 6 & 20.0 \\
\hline \multirow{3}{*}{ Occupation } & Non-working & 16 & 53.3 & 14 & 46.7 \\
\hline & Constant salary & 6 & 20.0 & 2 & 6.7 \\
\hline & Inconstant salary & 8 & 26.7 & 14 & 46.7 \\
\hline
\end{tabular}

Table (2): Frequency distribution of both groups in relation to present health history $(\mathrm{n}=60)$.

\begin{tabular}{|c|c|c|c|c|}
\hline \multirow{2}{*}{ Variables } & \multicolumn{2}{|c|}{ Study $(n=30)$} & \multicolumn{2}{|c|}{ Control $(n=30)$} \\
\hline & No. & $\%$ & No. & $\%$ \\
\hline $\begin{array}{l}\text { Present history: } \\
\text { Lung, mediastinal or pleural mass }\end{array}$ & 6 & 20.0 & 8 & 26.7 \\
\hline Pleural effusion & 5 & 16.7 & 3 & 10.0 \\
\hline Hyperhidrosis & 5 & 16.7 & 2 & 6.7 \\
\hline Recurrent spontaneous pneumothorax & 2 & 6.7 & 3 & 10.0 \\
\hline Myasthenia gravis & 1 & 3.3 & 0 & 0.0 \\
\hline Emphysema & 1 & 3.3 & 2 & 6.7 \\
\hline Thymoma & 1 & 3.3 & 0 & 0.0 \\
\hline
\end{tabular}




\begin{tabular}{|l|c|c|c|c|}
\hline \multirow{2}{*}{ Variables } & \multicolumn{2}{c|}{ Study (n=30) } & \multicolumn{2}{c|}{ Control (n=30) } \\
\cline { 2 - 5 } & No. & \% & No. & \% \\
\hline Massive hemothorax & 0 & 0.0 & 2 & 6.7 \\
\hline Mediastinal adenopathy & 3 & 10.0 & 1 & 3.3 \\
\hline Hiatal hernia & 1 & 3.3 & 0 & 0.0 \\
\hline Empyema & 1 & 3.3 & 1 & 3.3 \\
\hline Lobe bronchoctasis & 2 & 6.7 & 1 & 3.3 \\
\hline Bullous lung disease & 1 & 3.3 & 1 & 3.3 \\
\hline Others & 1 & 3.3 & 6 & 20.0 \\
\hline
\end{tabular}

Table (3): Frequency distribution of total patient knowledge for study group pre and post implementation of educational nursing protocol $(n=30)$.

\begin{tabular}{|c|c|c|c|c|c|}
\hline \multirow[t]{2}{*}{ Variables } & \multicolumn{2}{|c|}{$\begin{array}{l}\text { Pre- educational nursing } \\
\text { protocol }\end{array}$} & \multicolumn{2}{|c|}{$\begin{array}{l}\text { Post- educational } \\
\text { nursing protocol }\end{array}$} & \multirow{2}{*}{$\begin{array}{c}\text { Fisher's Exact } \\
\text { Test }\end{array}$} \\
\hline & $\mathbf{N}$ & $\%$ & $\mathbf{N}$ & $\%$ & \\
\hline Unsatisfied $<0.50 \%$ & 29 & 96.7 & 18 & 60.0 & \multirow{2}{*}{$0.001 * *$} \\
\hline Satisfied $>0.50 \%$ & 1 & 3.3 & 12 & 40.0 & \\
\hline
\end{tabular}

Table (4): Distribution of study group in relation to total practice about thoracoscopy pre and post implementation of educational nursing protocol $(n=30)$.

\begin{tabular}{|c|c|c|c|}
\hline Variables & & Mean \pm SD & p.v \\
\hline \multirow{2}{*}{ Total breathing and coughing exercises } & Pre & $.333 \pm 1.825$ & \multirow[t]{2}{*}{$0.001 * *$} \\
\hline & Post & $9.000 \pm 3.051$ & \\
\hline \multirow{2}{*}{ Total an incentive spirometer } & Pre & $.933 \pm 3.551$ & \multirow[t]{2}{*}{$0.004 *$} \\
\hline & Post & $5.133 \pm 6.861$ & \\
\hline \multirow{2}{*}{ Total foot and leg exercises } & Pre & $.466 \pm 2.556$ & \multirow[t]{2}{*}{$0.001 * *$} \\
\hline & Post & $12.533 \pm 3.277$ & \\
\hline \multirow{2}{*}{ Total hand and shoulders exercises } & Pre & $.666 \pm 3.651$ & \multirow{2}{*}{$0.001 * *$} \\
\hline & Post & $18.000 \pm 6.102$ & \\
\hline \multirow{2}{*}{ Total practice } & Pre & $2.4000 \pm 10.807$ & \multirow{2}{*}{$0.001 * *$} \\
\hline & Post & $44.6667 \pm 14.492$ & \\
\hline
\end{tabular}

$*=$ Significant difference, ${ }^{*} p \leq 0.05 \quad N s=$ Non significant difference, $p<0.05 * *=$ highly significance, $p \leq 0.01$

Table (5): Relation between knowledge and practice for study group $(n=30)$.

\begin{tabular}{|l|l|l|}
\hline \multicolumn{2}{|c|}{ Variables } & \multicolumn{1}{c|}{ Practice } \\
\hline \multirow{2}{*}{ Total patient knowledge } & Pearson Correlation & $\mathbf{. 5 4 4} * *$ \\
\cline { 2 - 3 } & Sig. (2-tailed) & $\mathbf{. 0 0 2}$ \\
\hline
\end{tabular}

**. Correlation is significant at the 0.01 level (2-tailed).

Table (6): Frequency distribution of study and control groups as regarding to patients' complications (n=60).

\begin{tabular}{|c|c|c|c|c|c|c|}
\hline \multirow{2}{*}{ Complications } & & \multicolumn{2}{|c|}{ Present } & \multicolumn{2}{|c|}{ Not present } & \multirow{2}{*}{$\begin{array}{c}\text { Fisher's } \\
\text { Exact Test }\end{array}$} \\
\hline & & No & $\%$ & No & $\%$ & \\
\hline \multirow{2}{*}{ Wound infection } & Study & 1 & 3.3 & 29 & 96.7 & \multirow{4}{*}{$.624 \mathrm{~ns}$} \\
\hline & Control & 2 & 6.7 & 28 & 93.3 & \\
\hline \multirow{2}{*}{ Pain or numbness at the incision site } & Study & 7 & 23.3 & 23 & 76.7 & \\
\hline & Control & 9 & 30 & 21 & 70 & \\
\hline
\end{tabular}

$*=$ Significant difference, ${ }^{*} p \leq 0.05 \quad N s=$ Non significant difference, $p<0.05 \quad * *=$ highly significance, $p \leq 0.01$ 
Table (1): Clarifies that, more than half of the study patients $(53.3 \%)$ and more than one third of the control patients $(33.3 \%)$ their age ranged from (18-29 years). About two thirds of both groups (study $63.3 \%$ and control $66.7 \%$ ) were male. More than half of patients in both groups were married. As regarding to level of education the highest percentage in study group (36.7\%) were highly educated and in control group $(33.3 \%)$ were not educated. As regard occupation more than half in study group $(53.3 \%)$ had no working and the highest percentages in control group $(46.7 \%)$ had no working with equal percentage had inconstant salary.

Table (2): Shows patients as regard present health history, it was noticed that less than one third in both groups were with diagnosis of lung, mediastinal or pleural mass (20\% and $26.7 \%$ ) respectively.

Table (3): Clarifies that, there was highly statistical significance difference between study group patients pretest and posttest in total knowledge after implementation of educational nursing protocol.

Table (4): Illustrates that, there was highly significance difference in total practice between pre and post implementation of educational nursing protocol for study group patients. This reveals improvement in practice of patients post protocol implementation.

Table (5): Show that, there was highly significant correlation between knowledge and practice of study group.

Table (6): Illustrates that wound infection and pain were the only complications happened and with higher percentages in control group than study group, but there was no statistical significance difference between study and control group patients as regard to complications.

\section{Discussion}

Complications of VATS procedures are rare and the frequency is estimated as $3-4 \%$ of treated patients. The most frequent complication is prolonged postoperative pleural tears causing air leaks from the lung that don't heal up quickly and that can keep the patient in the hospital a longer time and occasionally require additional treatment. The other significant complications are bleeding, infections, postoperative pain, recurrence at the port site and temporary or permanent nerve damage. Lung perforation, gas embolism and patients are also at risk of the complications of general anesthesia. Different complications of VATS procedures can occur with variable frequency in various diseases (Lochowski \& Kozak, 2014).

Based on the results of the present study; more than half of the study group patients and more than third of the control group patients their age ranged from
(18-29 years). The majority of both groups were male. More than half of patients in both groups were married. As regarding to level of education the highest percentage in study group were highly educated and in control group were not educated. As regard occupation more than half in study group had no working and the highest percentages in control group had no working with equal percentage had inconstant salary.

Schwarzbach et al., (2010) disagree with the current study as regard age of patients; he stated that the median age was 66 year in study group and 60 year in control group. But he agrees with the study as regard to sex which revealed that the majority of patients were male. He reported that there are no statistically significant differences in sex, age between both groups. This study supported by Elkhayat, (2014) who found in his study on thoracoscopic surgery at Assiut University that; the majority of patients were males. This study was in the same line with Hammad \& Saad, (2012) who found that, the mean age of the patients was 27.8 years (range 19-35).

As regarding to level of education, there was a simple difference between study and control group, but the occurrence of complications not affected by this difference and there was no statistical significance difference between both groups.

As regarding to diagnosis, it was noticed that the highest percentage of patients had lung, mediastinal or pleural mass with no significant difference between both groups as regarding to type of operation with the highest percentage underwent lung resection surgery in both groups.

These results in the same line with Schwarzbach et al., (2010) who reported that the majority of patients in both groups underwent VATS for diagnostic or therapeutically pulmonary wedge resection. The most common underlying diagnoses were malignancies in both groups.

El khayat, (2014) reported that, most common disease operated upon were undiagnosed pleural effusion follow by mediastinal mass then clotted hemothorax after trauma, pneumothorax, empyema; hyperhidrosis and finally bullous lung disease.

The present study revealed that, there was highly statistical significance difference in total knowledge between pre and post protocol implementation for study group patients. This result was supported by Brunetti et al., (2013) who told that preoperative educational program helps to set expectations about surgical and anesthetic procedures and may diminish fear, fatigue and pain and enhance recovery and early discharge. Verbalized education, leaflets and multimedia information containing explanations of the procedure and cognitive interventions may 
improve pain control, nausea and anxiety after surgery.

Refai et al., (2018) revealed that, a preoperative personal education may play a key role to reduce stress, fear or anxiety and improve the morbidity of patients, enabling them to achieve functional and psychological compensatory mechanisms more quickly. Preoperative patient education performed using verbal, written or multimedia materials to make the patient a potentially active participant and the main character of recovery, able to positively impact self throughout the surgical and healing process .

Sebio Garcia et al., (2016) reported that education provides beneficial effects with no evidence of harm. In particular, pain control appears better following lung resection. It is recommended that patients should routinely receive devoted preoperative education and concluded that education is beneficial, but, because of study heterogeneity, the exact duration, intensity, structure and patient selection to achieve maximum efficacy is uncertain.

The present study found that, there was highly significance difference in total practice between pre and post protocol implementation for study group patients. The findings of this study are in agreement with those of Pehlivan et al., (2011) who proved that preoperative prophylactic physiotherapy has been shown to be an important and effective approach in preventing or reducing postoperative complications, in addition to enhancing treatment by familiarizing the patient with the physiotherapeutic procedures.

Batchelor et al., (2018) mentioned that preoperative exercise rehabilitation program can reduce hospital stay and postoperative pulmonary complications. Because of study heterogeneity, no firm recommendations can be made on the nature of the intervention in terms of exercise modality, delivery, frequency or preoperative duration. Preoperative exercise program should be considered for patients with borderline lung function or exercise capacity.

Boujibar et al., (2018) reported that physical activities are method of disease control and treatment for patients. In particular, exercise has positive effects on physical and mental health and is vital for patients who feel their quality of life has deteriorated due to physical, psychological, emotional, and financial hardships.

This study found that, there was highly significant correlation between knowledge and practice of study group. The findings of the present study are supported by C. Deasy et al., (2014) who revealed that perioperative rehabilitation strategies recommended to prevent postoperative complications include lung expansion interventions, deep breathing exercises, incentive spirometry and ambulation.
The present study found that, wound infection and pain were the only complications happened and with higher percentages in control group than study group patients, but there was no significance difference between study and control group patients as regard to complications. Lochowski \& Kozak, (2014) reported that, complications of VATS procedures are rare and the frequency is estimated as $3-4 \%$ of treated patients.

Valenzuela et al., (2017) in the same line with the current study who mentioned that shorter hospital stays with lower postoperative complications were found in the preoperative physiotherapy education group, the differences were not significant. There was no significant differences in the types of complications between the groups ( $p>0.05)$.

Sebio Garcia et al., (2016) pre-operative education has a positive impact on the occurrence and severity of postoperative complications after pulmonary lobectomy by minimally invasive surgery.

\section{Conclusion}

The result of the present study concluded that; there were improvements in total knowledge and practice after educational nursing protocol implementation. Improving patients' knowledge and practice in study group had a favorable effect in reducing postoperative complications than in control group. Wound infection and pain were the only complications happened and with higher percentages in control group than study group with no significance difference between study and control group patients.

\section{Recommendations}

Based on the findings of present study, the following recommendations are suggested:

\section{For patients}

- Educational nursing protocol should be given for patients in the form of video to be more understandable.

- Encourage patients to participate in group teaching regarding thoracoscopic surgery.

- Increase patients' awareness about the importance of periodic check up to prevent developing any complications.

- Establishment of ahot line (phone and net) contact for urgent consultations.

\section{For administration}

- A written educational hand book should be available for each patient in simplified term and containing simple pictures and distributed among thoracoscopic patients to provide them with the needed information. 


\section{For research}

- Replication of the study on a larger probability sample selected from different geographical areas in Egypt is recommended to obtain more generalizable data.

\section{References}

1. Agostini, P., Lugg, S., Adams, K., Vartsaba, N., Kalkat, M., Rajesh, P., Steyn, R., Naidu, B., Rushton, A., \& Bishay, E., (2017): Postoperative pulmonary complications and rehabilitation requirements following lobectomy: a propensity score matched study of patients undergoing video-assisted thoracoscopic surgery versus thoracotomy. Interactive cardiovascular and thoracic surgery, 24(6), pp.931-937.

2. Batchelor, T., Rasburn, N., AbdelnourBerchtold, E., Brunelli, A., Cerfolio, R., Gonzalez, M., Ljungqvist, O., Petersen, R., Popescu, W., Slinger, P., \& Naidu, B., (2018): Guidelines for enhanced recovery after lung surgery: recommendations of the Enhanced Recovery After Surgery (ERAS $®)$ Society and the European Society of Thoracic Surgeons (ESTS). European Journal of Cardio-Thoracic Surgery, 55(1), pp.91-115.

3. Berry M., (2015): Pulmonary Artery Bleeding During Video-Assisted Thoracoscopic Surgery: Intraoperative Bleeding and Control. Thorac Surg Clin. 25 (3), Pp: 239-47.

4. Boujibar, F., Bonnevie, T., Debeaumont, D., Bubenheim, M., Cuvellier, A., Peillon, C., Gravier, F., \& Baste, J., (2018): Impact of prehabilitation on morbidity and mortality after pulmonary lobectomy by minimally invasive surgery: a cohort study. Journal of thoracic disease, 10(4), p.2240.

5. Brunetti M., Shemilt I., Pregno S., Vale L., Oxman A., \& Lord J., (2013): GRADE guidelines: 10. Considering resource use and rating the quality of economic evidence. J Clin Epidemiol 2013; 66:140-50.

6. C. Deasy, B., Coughlan, J., Pironom, D., Jourdan, \& P., Mannix-McNamara., (2014): "Psychological distress and coping amongst higher education students: a mixed method enquiry," PLoS ONE, vol. 9, no. 12, Article ID e115193. View at Publisher. View at Google Scholar · View at Scopus

7. El khayat, H., (2014): Introducing Thoracoscopic Surgery in Assiut University Hospitals; 2 years results and outcomes. Cardiothoracic Surgery Department, Faculty of Medicine, Assiut University, Assiut, Egypt.
8. Gao, K., Yu, P., Su, J., He, C., Liu, L., Zhou, Y., Pu, Q., \& Che, G., (2015): Cardiopulmonary exercise testing screening and pre-operative pulmonary rehabilitation reduce postoperative complications and improve fast-track recovery after lung cancer surgery: A study for 342 cases. Thoracic cancer, 6(4), pp.443-449.

9. Guerrini G., Lo Faso F., Vagliasindi A., Lembo R., Solaini L., \& Soliani P., (2016): The Role of Minimally Invasive Surgery in the Treatment of Lung Metastases. J Invest Surg. Pp: $1-6$.

10. Hammad, A., \& Saad, M., (2012): Life quality after video-assisted thoracoscopic thoracic sympathetic chain clipping for patients with isolated primary palmar hyperhidrosis. Journal of the Arab Society for Medical Research, 7(2), 63-67.

11. Irons J., Miles L., Joshi K., Klein A., Scarci M., \& Solli P., (2016): Intubated Versus Nonintubated General Anesthesia or VideoAssisted Thoracoscopic Surgery-A CaseControl Study. J Cardiothorac Vasc Anesth.

12. Lochowski, M., \& Kozak, J., (2014): Videoassisted thoracic surgery complications. Videosurgery and Other Miniinvasive Techniques, 9(4), p.495.

13. Mu J., Chen G., \& Sun K., (2013): Application of video-assisted thoracic surgery in the standard operation for thoracic tumors. Cancer Biol Med. 10(1), Pp: 28-35.

14. Pehlivan E., Turna A., Gurses A., Gurses H., (2011): The effects of preoperative short-term intense physical therapy in lung cancer patients: a randomized controlled trial. Ann Thorac Cardiovasc Surg; 17:461-468.

15. Refai, M., Andolfi, M., Gentili, P., Pelusi, G., Manzotti, F., \& Sabbatini, A., (2018): Enhanced recovery after thoracic surgery: patient information and care-plans. Journal of thoracic disease, 10(Suppl 4), S512.

16. Schwarzbach, M., Ronellenfitsch, U., Wang, Q., Rössner, E., Denz, C., Post, S., \& Hohenberger, P., (2010): Effects of a clinical pathway for video-assisted thoracoscopic surgery (VATS) on quality and cost of care. Langenbeck's archives of surgery, 395(4), 333-340.

17. Sebio Garcia R., Ya' $\mathbf{Y a}^{\prime}$ nez Brage M., Gime'nez Moolhuyzen E., Granger C., Denehy L., (2016): Functional and postoperative outcomes after preoperative exercise training in patients with lung cancer: a systematic review and meta-analysis. Interact CardioVasc Thorac Surg 2016; 23:486-97. 
18. Steven K., Thompson, (2012): sample size,pP :59-60.

19. Valenzuela, F., Fernández, I., Cirre, M., Sánchez-Palencia, A., \& de Guevara, A., (2017): Impact of major video-assisted thoracoscopic surgery on care quality. Journal of thoracic disease, 9(11), 4454.

20. Vallance A., Tcherveniakov P., Bogdan C., Chaudhuri N., Milton R., \& Kefaloyannis E., (2016): The evolution of intraoperative conversion in video assisted thoracoscopic lobectomy. Ann R Coll Surg Engl, 9.Pp:1-5.

21. White, J., \& Dixon, S., (2015): Nurse led Patient Education Programme for patients undergoing a lung resection for primary lung cancer. Journal of thoracic disease, 7(Suppl 2), S131.

22. Yeung W., (2016): Post-operative care to promote recovery for thoracic surgical patients: a nursing perspective. Journal of thoracic disease, 8 (Suppl 1), P: 71. 